\title{
Volatility of methylglyoxal cloud SOA formed through OH radical oxidation and droplet evaporation
}

Diana L. Ortiz-Montalvo ${ }^{1,3}$, Allison N. Schwier², Yong B. Lim ${ }^{1,4}$, V.Faye McNeill ${ }^{2}$, Barbara J. Turpin $^{5^{*}}$

$10{ }^{4}$ Center for Environment, Health and Welfare Research, Korea Institute of Science and Technology, 11 Seoul 02792, Republic of Korea

${ }^{5}$ Environmental Science and Engineering, University of North Carolina, Chapel Hill, NC, USA

*Corresponding author. Phone: (919) 966-3013; email: bjturpin@email.unc.edu

\section{Abstract}

The volatility of secondary organic aerosol (SOA) formed through cloud processing (aqueous

hydroxyl radical ('OH) oxidation and droplet evaporation) of methylglyoxal (MGly) was studied.

21 Effective vapor pressure and effective enthalpy of vaporization ( $\left.\Delta H_{\text {vap }, \text { eff }}\right)$ were determined using 1$)$

22 droplets containing MGly and its oxidation products, 2) a Vibrating Orifice Aerosol Generator

23 (VOAG) system, and 3) Temperature Programmed Desorption Aerosol-Chemical Ionization Mass

24 Spectrometry (TPD Aerosol-CIMS). Simulated in-cloud MGly oxidation (for 10-30 min) produces

25 an organic mixture of higher and lower volatility components with an overall effective vapor

26 pressure of $(4 \pm 7) \times 10^{-7}$ atm at $\mathrm{pH} 3$. The effective vapor pressure decreases by a factor of 2 with

27 addition of ammonium hydroxide $(\mathrm{pH} 7)$. The fraction of organic material remaining in the particle-

28 phase after drying was smaller than for similar experiments with glycolaldehyde and glyoxal SOA.

29 The $\Delta H_{\text {vap,eff }}$ of pyruvic acid and oxalic acid + methylglyoxal in the mixture (from TPD AerosolCIMS) were smaller than the theoretical enthalpies of the pure compounds and smaller than that 
31 estimated for the entire precursor/product mix after droplet evaporation. After 10-30 min of

32 aqueous oxidation (one cloud cycle) the majority of the MGly $+{ }^{\circ} \mathrm{OH}$ precursor/product mix (even

33 neutralized) will volatilize during droplet evaporation; neutralization and at least 80 min of oxidation

34 at $10^{-12} \mathrm{M}^{\bullet} \mathrm{OH}$ (or $>12 \mathrm{hr}$ at $10^{-14} \mathrm{M}$ ) is needed before low volatility ammonium oxalate exceeds

35 pyruvate.

\section{Introduction}

There is substantial evidence for secondary organic aerosol (SOA) formation through gas-

39 phase oxidation followed by aqueous chemistry in clouds and wet aerosol (Blando and Turpin, 2000;

40 Ervens et al., 2011; Herrmann et al., 2015). Organic compounds are predominantly emitted in the

41 gas-phase (Fraser et al., 1996) where they are fragmented, oxidized and form small water-soluble

42 organic compounds, which are ubiquitous and abundant in the atmosphere (Millet, 2005; Carlton and

43 Turpin, 2013). The chemistry of several water-soluble organics (e.g., aldehydes, organic acids,

44 ketones, phenols, epoxides) has been studied because of their potential to form SOA in the aqueous-

45 phase $\left(\mathrm{SOA}_{\mathrm{aq}}\right)$ by means of radical chemistry (e.g., hydroxyl radical reactions) and non-radical

46 reactions (e.g., acid or ammonium catalyzed reactions) (e.g., Ervens et al., 2011; De Haan et al.,

47 2011; McNeill, 2015). SOA $a$ has also been observed to form through evaporation of droplets

48 containing single organic compounds (e.g., glyoxal, methylglyoxal) that form oligomers through

49 self-reactions (Loeffler et al., 2006; De Haan et al., 2009). The current study focuses on droplet

50 evaporation of products formed by the $\mathrm{OH}$-initiated oxidation of methylglyoxal (MGly) with

51 hydroxyl radicals $\left({ }^{\circ} \mathrm{OH}\right)$ in clouds (MGly SOACld).

MGly $\left(\mathrm{C}_{3} \mathrm{H}_{4} \mathrm{O}_{2}\right)$ is a secondary gas-phase oxidation product of anthropogenic and biogenic

53 hydrocarbons including isoprene (Atkinson and Arey, 2003; Seinfeld and Pandis, 2012; Fu et al.,

54 2008). MGly is emitted by biomass burning (Hays et al., 2002), vehicles (Ban-Weiss et al., 2008)

55 and from the sea surface (Lawson et al., 2015). Its gas-phase lifetime is $2 \mathrm{hr}$ and $9 \mathrm{hr}$ with respect to

56 photolysis and ${ }^{\circ} \mathrm{OH}$, respectively (Atkinson 2000). MGly is water soluble (effective Henry’s law

57 constant, $\mathrm{H}_{\mathrm{eff}}=3.71 \times 10^{3} \mathrm{M} \mathrm{atm}^{-1}$ at $\left.25^{\circ} \mathrm{C}\right)($ Betterton and Hoffmann, 1988) and has been measured 
in clouds $(<0.3-128 \mu \mathrm{M})$ (Munger et al., 1995). In the aqueous-phase, MGly reacts rapidly with ${ }^{\circ} \mathrm{OH}$

59 ( 26 min aqueous lifetime with respect to $\left.{ }^{\circ} \mathrm{OH}\right)$ and forms several products found in the particle-

60 phase in the atmosphere (e.g., pyruvate, oxalate, and glyoxylate; Limbeck et al., 2001). At cloud

61 relevant concentrations, the reaction of MGly with ${ }^{\circ} \mathrm{OH}$ produces small carboxylic acids, mainly

62 pyruvic, acetic, and oxalic acids, and to a minor extent glyoxylic and glycolic acids (Tan et al.,

63 2010). In the highly concentrated solutions found in wet aerosols, non-radical (e.g., $\mathrm{NH}_{4}^{+}$) reactions

64 become more important and radical reactions can form larger organic acids and oligomers (Lim et

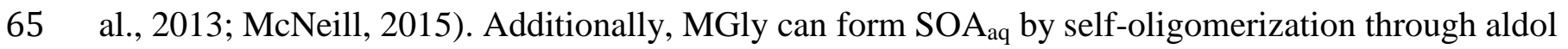

66 condensation reactions in evaporating aqueous droplets (Loeffler et al., 2006; De Haan et al., 2009).

While $\mathrm{SOA}_{\mathrm{aq}}$ formation is being added to chemical transport models (McNeill, 2015), a

better understanding of chemical transformations that occur during droplet evaporation (Loeffler et

al., 2006; De Haan et al., 2009; Ortiz-Montalvo et al., 2012, 2014) and the thermodynamic properties

of the $\mathrm{SOA}_{\mathrm{aq}}$ mixture are needed to aid these efforts (Tsigaridis and Kanakidou, 2003). Michaud et

al. (2009) found that $\mathrm{SOA}_{\mathrm{aq}}$ formed through aqueous $\mathrm{OH}$ oxidation of methacrolein and droplet

evaporation became less volatile with increasing oxidation (reaction time). Ortiz-Montalvo et al.

(2012) provided values of effective vapor pressure $\left(\sim 10^{-7} \mathrm{~atm}\right)$ and enthalpy of vaporization $(\sim 70$

$\mathrm{kJ} / \mathrm{mol}$ ) for the precursor/product mixture formed through aqueous ${ }^{\circ} \mathrm{OH}$ oxidation (10-30 min) and

droplet evaporation of glycolaldehyde. They hypothesized that the vapor pressure of glycolaldehyde

$\mathrm{SOA}_{\mathrm{aq}}$ would be orders of magnitude lower if the organic acid products (e.g. oxalate) were

neutralized to organic salts. Evidence to support this was provided by evaporating droplets of oxalic acid and ammonium oxalate. More recently, Ortiz-Montalvo et al. (2014) verified that the volatility

of a glyoxal $+{ }^{\circ} \mathrm{OH}$ precursor/product mixture (after 10 min reaction) was significantly reduced when the mixture was neutralized from $\mathrm{pH} 3$ to $\mathrm{pH} 7$ through the addition of ammonium hydroxide.

The present study provides, to our knowledge, the first reported estimates of the effective 
2.1 Overview

The purpose of this work is to characterize the volatility of SOACld formed from in-cloud

88 oxidation of MGly by $\mathrm{OH}$ radicals $\left({ }^{\circ} \mathrm{OH}\right)$ followed by droplet evaporation. Vibrating Orifice Aerosol

89 Generator (VOAG) and Temperature Programmed Desorption Aerosol Chemical Ionization Mass

90 Spectrometry (TPD Aerosol-CIMS) systems were used to determine $p_{L, \text { eff. }}^{\prime}$ and $\Delta H_{v a p, \text { eff }}$ of the MGly

$91+{ }^{\circ} \mathrm{OH}$ precursor/product mix in evaporating droplets for two different atmospheric scenarios. The

92 aqueous chemistry of MGly and ${ }^{\circ} \mathrm{OH}$ has previously been validated by comparing predicted and

93 measured precursor/product concentration dynamics in laboratory batch reactor experiments (Tan et

94 al., 2010; Lim et al., 2013). We used this chemistry to determine the precursor/product compositional

95 mix resulting from the ${ }^{\circ} \mathrm{OH}$ oxidation $\left(10^{-12} \mathrm{M}\right)$ of $5 \mu \mathrm{M}$ MGly in cloud droplets (10-30 min) using 1)

96 a batch reactor and 2) a continuously stirred tank reactor (CSTR) approximation. Mimic solutions

97 prepared with these compositions were used in droplet evaporation experiments. The VOAG system

98 provided information about the volatility behavior of the mixture, whereas the TPD Aerosol-CIMS

99 characterized the behavior of individual species within the mixture.

$100 \quad 2.2$ Chemical Modeling

101 Previously published chemical models were used (Tan et al., 2010; Lim et al., 2013). In batch

102 reactor modeling (Tan et al., 2010), the initial MGly concentration was $5 \mu \mathrm{M}$, within the

103 concentration range found in cloud water (Munger et al., 1995). This corresponds to a gas-phase

104 MGly concentration of $\sim 1 \mathrm{ppb}$, given a Henry's law constant of $\mathrm{H}=3.71 \times 10^{3} \mathrm{M} \mathrm{atm}^{-1}$ (Betterton

105 and Hoffmann, 1988). MGly decreased as the reaction proceeded. The concentration of ${ }^{\circ} \mathrm{OH}$ was

106 held constant at $10^{-12} \mathrm{M}$, an upper bound for cloud water (Ervens et al., 2014). For CSTR modeling

107 (Lim et al., 2013), the aqueous MGly concentration was maintained always at $5 \mu \mathrm{M}$ and the ${ }^{\circ} \mathrm{OH}$

108 concentration at $10^{-12} \mathrm{M}$. Note, modeled composition at $10^{-13}$ and $10^{-14} \mathrm{M} \mathrm{OH}$ are provided in Fig.

109 S1.

MGly is formed in the atmosphere from many precursor gases; thus it is not immediately

111 apparent whether the batch reactor or CSTR approximation is more appropriate for modeling the 
112 chemical composition. If gas-phase production of MGly is slow relative to its aqueous oxidation, a

113 batch reactor may be a better approximation. If, on the other hand, gas-phase MGly production (and

114 aqueous uptake) is rapid relative to aqueous oxidation, MGly will continue to be replenished in the

115 aqueous-phase as oxidation takes place, and the aqueous oxidation system will be better represented

116 as a CSTR. However, you will find below that effective vapor pressures determined for both Batch

117 and CSTR assumptions were similar. This chemistry is likely to be oxidant (rather than MGly)

118 limited (Ervens et al., 2014).

$119 \quad 2.3$ Mimic Samples

120 Mimic solutions were prepared to match the chemical composition 10-30 minutes into batch

121 and CSTR reactions. Concentrations of species were scaled up 13-130 times for CSTR, and 25-250

122 times for batch) creating 6 concentrations from approximately 500-4000 $\mu \mathrm{M}-\mathrm{C}$ all above the

123 detection limits of the droplet evaporation system, while maintaining the same distribution of

124 species. Thus, droplet evaporation experiments were conducted with solutions that were initially

125 more concentrated than typical cloud droplets and as a result, experiments do not include any

126 chemistry that occurs at the initial (most dilute) stage of droplet evaporation. Mimics were prepared

127 using $18 \mathrm{M} \Omega$ milli-Q water, methylglyoxal (37.8\%; Sigma-Aldrich) and pyruvic (99.1\%; Sigma-

128 Aldrich), oxalic (0.1008 N; Fluka Analytical), and acetic (99.99\%; Sigma-Aldrich) acids. To study

129 the effects of increasing $\mathrm{pH}$, we added ammonium hydroxide (29.6\% as ammonia $\left(\mathrm{NH}_{3}\right)$; J.T. Baker)

130 to selected CSTR mimics.

1312.4 VOAG Droplet Evaporation Experiments

132 Monodisperse droplets (droplet diameter, $D_{d}=17.9 \pm 0.4 \mu \mathrm{m}, n=3, r^{2}=0.99$ ) of mimic samples

133 were generated and evaporated using a VOAG (TSI Model 3450; Berglund and Liu, 1973) followed

134 by a dilution drying chamber (residence time $6 \mathrm{~s}, 12 \pm 3 \% \mathrm{RH}, 24.1 \pm 0.4^{\circ} \mathrm{C}$ ). The diameter of the

135 resulting particles (e.g., SOA) was measured with an optical particle counter (OPC) downstream of

136 an ionizer, as described previously (Ortiz-Montalvo et al., 2012) and in Supplemental Information. 
138 Briefly, six dilutions (0 - $4000 \mu \mathrm{M} \mathrm{C})$ of each mimic solution and organic standard (acetic, oxalic,

139 succinic, glutaric, and tartaric acids) were passed through the VOAG. Resulting droplets were dried 140 to $\sim 10 \% \mathrm{RH}$; their dry diameter was measured in the OPC and the mass of residual particles (PM

141 mass) was calculated using assumptions given in Table S1). In addition, each mimic solution was

142 analyzed for total organic carbon (TOC) and converted to organic matter (OM mass). The PM mass

143 of the organic standards was regressed on OM mass, and the slopes of each were evaluated against

144 their corresponding liquid vapor pressures $\left(p^{\circ} \mathrm{L}\right)$ (SIMPOL group contribution method; Pankow and

145 Asher, 2008) and enthalpies of vaporization $\left(\Delta H_{\text {vap }}\right)$ (Joback and Reid, 1987; group contribution

146 method using normal boiling points to estimate $\Delta H_{v a p}$ of pure compounds). Sigmoidal fits were

147 obtained since the PM mass divided by droplet OM mass (PM mass / OM mass(droplet)) reflects the

148 particle fraction (i.e., fraction of the total droplet organic matter that remained in the particle-phase).

149 Because some organic compounds, like tartaric acid, retain water even at 5\% RH (Peng et al., 2001),

150 a correction was made to the original sigmoidal curve to account for the effect of residual water on

151 particle density, as described previously (Ortiz-Montalvo et al., 2012). The $p_{L, \text { eff }}^{\prime}$ and $\Delta H_{\text {vap,eff }}$ of the

152 mimics (mix of MGly precursors and products) were estimated from the corrected sigmoidal curves.

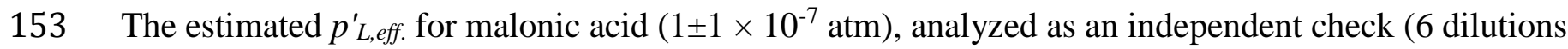

154 between 0-3000 $\mu \mathrm{M} \mathrm{C}$ from $0.999 \%$, Sigma-Aldrich), is of the same order of magnitude as the

155 calculated theoretical value $\left(2 \pm 2 \times 10^{-7} \mathrm{~atm}\right)$ (Pankow and Asher, 2008). The estimated $\Delta H_{\text {vap,eff. }}$

$156(72 \pm 2 \mathrm{~kJ} / \mathrm{mol})$ differed from the theoretical value by $4 \%(69.12 \pm 1.79 \mathrm{~kJ} / \mathrm{mol})(\mathrm{Joback}$ and Reid,

157 1987). A 17\% uncertainty is introduced because of differences in refractive index of malonic acid

158 (1.479) and polystyrene latex particles (1.59; used for OPC manufacturer-supplied calibration). Droplet evaporation experiments were also run with $1 \mathrm{mM}$ standards: oxalic acid, oxalic acid

$160+$ ammonium hydroxide, ammonium oxalate (99.0\%; Fluka Analytical), pyruvic acid, pyruvic acid + 161 ammonium hydroxide, and sodium pyruvate (100 mM; Thermo Scientific) (Fig. 1). Ammonium

162 hydroxide, when used, was added to adjust the solution to $\mathrm{pH}$ 7. The ratio of the residual PM volume 
to $O M \operatorname{mass}_{(\text {droplet })}(P M$ vol. / OM mass $($ droplet $)$ ) for oxalic acid + ammonium hydroxide was identical

164 to that of ammonium oxalate, verifying that the addition of ammonium hydroxide effectively

165 neutralized organic acids (Fig. 1). Note that $P M$ vol. / OM mass (droplet) $_{\text {is }}$ is proportional to the fraction

166 remaining in the particle-phase and increases with decreasing vapor pressure. In addition,

167 neutralization of oxalic acid (ammonium oxalate production) had a larger effect on PM vol. / OM

168 mass (droplet) $_{\text {than }}$ than pyruic acid neutralization (Fig. 1), presumably because ammonium oxalate has a

169 lower vapor pressure (Paciga et al., 2014).

$170 \quad 2.5$ TPD Aerosol-CIMS Analysis

171 Bulk mimic solutions were also analyzed by TPD Aerosol-CIMS, as described previously

172 (Ortiz-Montalvo et al., 2014; Drozd et al., 2014; Hakkinen et al., 2014; McNeill et al., 2007).

173 Briefly, bulk mimic solutions were aerosolized, dried and combined with a dry $\mathrm{N}_{2}$ dilution flow (3.5-

$1749.5 \mathrm{~L} / \mathrm{min}$ ) to $\sim 12 \% \mathrm{RH}$. The aerosol had a lognormal number size distribution with a geometric

175 mean particle diameter of $29 \pm 3 \mathrm{~nm}$ and geometric standard deviation of 1.3 (measured by scanning

176 mobility particle sizer after drying). Organics were then volatilized at $25-116^{\circ} \mathrm{C}$ for gas-phase

177 detection by CIMS (McNeill et al., 2007; Ortiz-Montalvo et al., 2014). The residence time from

178 atomization to CIMS detection was $\sim 6$ seconds. CIMS measurements were made in negative mode

179 using I reagent ions.

180 MGly and oxalic, pyruvic and acetic acids are detectable in the negative mode. Oxalic acid

181 and MGly both appear at $m / z 217$ as $\mathrm{I}^{-} \cdot \mathrm{C}_{2} \mathrm{H}_{2} \mathrm{O}_{4}$ and $\mathrm{I}^{-} \cdot \mathrm{C}_{3} \mathrm{H}_{4} \mathrm{O}_{2} \cdot \mathrm{H}_{2} \mathrm{O}$, respectively. Pyruvic acid

182 appears at $m / z, 215$ as $\mathrm{I}^{-} \cdot \mathrm{C}_{3} \mathrm{H}_{4} \mathrm{O}_{3}$. Acetic acid is detected at $m / z 187$ as $\mathrm{I}^{-} \cdot \mathrm{C}_{2} \mathrm{H}_{4} \mathrm{O}_{2}$; however, no

183 analysis of acetic acid was performed because initial evaluations showed a constant signal over the

184 range of temperature tested, suggesting it was present entirely in the gas-phase at $25^{\circ} \mathrm{C}$. The

185 Clausius-Clapeyron relation was used to calculate the $\Delta H_{\text {vap, eff. }}(\mathrm{kJ} / \mathrm{mol})$ for individual species

186 present in the mixture (Ortiz-Montalvo et al., 2014).

Each mimic solution was analyzed at least twice. A solution of $1 \mathrm{mM}$ oxalic acid standard

188 (from 0.05 M; Fluka Analytical) was also analyzed (only once); its measured $\Delta H_{v a p, e f f . ~}(69 \pm 33$ 
$189 \mathrm{~kJ} / \mathrm{mol}$ ) was within $22-29 \%$ of the theoretical value $(91-101 \mathrm{~kJ} / \mathrm{mol}$; Yaws, 2003) for the temperature 190 range used $\left(25-37^{\circ} \mathrm{C}\right)$.

\section{3. Results}

\section{3.1 Modeled Droplet Composition}

Precursor and product concentration dynamics as well as composition of mimics at 10 and 30

194 minutes are shown (Fig. 2) because these are typical cloud droplet life times (Desboeufs et al., 2003;

195 Ervens and Volkamer, 2010). Among the four mimics, the $30 \mathrm{~min}$ Batch and $10 \mathrm{~min}$ CSTR mimic

196 samples were the most different. Therefore, we selected these for droplet evaporation experiments, in

197 order to bound the range of $p_{L, \text { eff. }}^{\prime}$ and $\Delta H_{\text {vap, eff. }}$ of the precursor/product mixtures formed after one

198 cloud processing cycle of MGly in the presence of ${ }^{\circ} \mathrm{OH}$. (Note, an air mass encountering cloudy

199 conditions typically undergoes multiple ( 10) cloud cycles of 10-30 min duration over the course of

200 a day (Ervens and Volkamer, 2010).) The continuous accumulation of pyruvic acid (pink line)

201 observed in the CSTR model is due to the continuous dissolution of gas-phase MGly in the CSTR

202 model. Formaldehyde mainly forms from the reaction of ${ }^{\circ} \mathrm{OH}$ and acetic acid (a major product of

203 MGly + $\left.{ }^{\circ} \mathrm{OH}\right)$ (Tan et al., 2012; Lim et al., 2013).

2043.2 VOAG - Vapor Pressure and Enthalpy of Vaporization

205 The $p_{L, \text { eff. }}^{\prime}$ and $\Delta H_{\text {vap,eff. }}$ of CSTR and Batch mimics were comparable: $3-6 \times 10^{-7}$ atm and 67-

20669 kJ/mol, respectively (Table 1, Figs. 3 and S1). The 30 min Batch mimic, which had a higher

207 percentage of organic acids and less MGly, had a slightly lower but not significantly different $p_{L, e f f}^{\prime}$

208 than the 10 min CSTR mimic ( $p=0.01$, t-test, two-tailed). Similarly, the reduction in $p_{L, e f f}^{\prime}$

209 accomplished by neutralization ( $\mathrm{pH}$ 7) of the CSTR mimic was small (factor of two) and the

210 difference was not significant ( $p=0.01$, t-test, two-tailed).

211 Fig. 3 shows the residual particle mass (PM mass) and mass of organic matter in the droplet

$212($ OM mass $($ droplet $))$ from droplet evaporation experiments conducted with organic acid standards and

213 mimics. The PM mass of organic acid standards (oxalic, succinic, glutaric, and tartaric acids) is well

214 correlated with $O M \operatorname{mass}_{(\text {droplet })}\left(r^{2}=0.84-0.99\right)$ with the exception of acetic acid, which is volatile. 
215 The slopes (PM mass / OM mass(droplet) $)$ reflect the fraction of total droplet organic matter remaining

216 in the particle-phase (e.g., particle fraction) and are reported in Table 1 with coefficients of

217 determination $\left(r^{2}\right)$ of PM mass on $O M$ mass $_{(\text {droplet })}$ for Batch 30 min (solid blue circles) and CSTR 10

$218 \min ($ at $\mathrm{pH} 3$ and $\mathrm{pH} 7$; solid black triangles and red squares, respectively). SOA yields are reported

219 in Section S3. The sample with the highest particle fraction was the neutralized (pH 7) 10 min CSTR

220 mimic. In contrast, the sample with the lowest particle fraction was the $10 \mathrm{~min} \mathrm{pH} 3 \mathrm{CSTR}$ mimic.

221 The sigmoidal curve in the inset of Fig. 3 is a fit to the PM mass / OM mass(droplet) versus log

$222 p_{L}^{\circ}$ for the organic acid standards, uncorrected (dashed) and corrected (solid) for the upper bound

223 influence of retained water on density. Also shown in the inset are the corresponding PM mass / OM

$224 \operatorname{mass}_{(\text {droplet })}$ values for the Batch (inset middle blue dashed arrow) and CSTR samples (inset upper red

225 arrow for $\mathrm{pH} 7$; lower green dashed arrow for $\mathrm{pH} 3$ ), pointing to their corresponding estimated $p_{L, \text { eff. }}^{\prime}$

226 The $p_{L, \text { eff }}^{\prime}$ values, taken from the sigmoidal regression, are reported in Table 1. Overall, the

227 volatilities of the three mimics were within a factor of two, with the largest difference found between

228 the $10 \mathrm{~min}$ CSTR mimic at $\mathrm{pH} 7\left(3 \times 10^{-7} \mathrm{~atm}\right)$ and $\mathrm{pH} 3\left(6 \times 10^{-7} \mathrm{~atm}\right)$. There was a factor of two

229 decrease in volatility with increasing $\mathrm{pH}$. A decrease in volatility with addition of ammonium is

230 consistent with lower reported vapor pressures of organic acid salts compared to their corresponding

231 acids (Fig. 1). The decrease is modest presumably because of the modest effect of ammonia addition

232 on pyruvic acid (compared to the much larger effect of ammonia addition on oxalic acid).

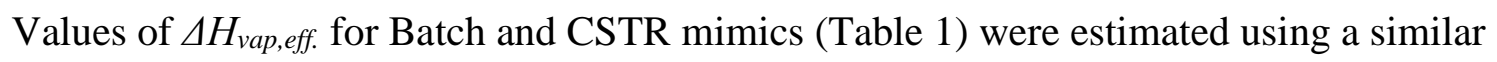

234 approach (Fig. S2). $\Delta H_{\text {vap,eff }}$ estimates $(\sim 68 \mathrm{~kJ} / \mathrm{mol})$ for the mix of MGly $+{ }^{\circ} \mathrm{OH}$ precursors and

235 products (mimics) fall within the range of the $\Delta H_{v a p}$ values of the pure individual components that

236 comprised the CSTR and Batch samples (23-73 kJ/mol, at normal boiling point; Yaws 2003). No

237 significant difference was observed between $\Delta H_{\text {vap, eff }}$ estimates for the different mimics. A difference

238 of $\sim 40-50 \%$ is observed between theoretical (molar-weighted enthalpies) and effective $\Delta H_{v a p}$ (Table

239 1). Possible reasons are discussed below. 
241 through one cloud cycle $(10-30 \mathrm{~min})$ has a $p_{L, \text { eff }}^{\prime}$ and $\Delta H_{v a p, e f f .}$ of $(4 \pm 7) \times 10^{-7} \mathrm{~atm}$ and $68 \pm 3 \mathrm{~kJ} / \mathrm{mol}$,

242 respectively. Note that longer in-cloud reaction times (i.e., multiple cloud cycles) will push the

243 product mix toward oxalate, which if present as a salt would lower the volatility of the mixture

244 substantially (see ammonium oxalate slopes, Fig.1). Ammonium oxalate has a vapor pressure of

$245 \sim 10^{-11}$ atm (U.S. EPA 2010).

2463.3 TPD Aerosol-CIMS - Enthalpy of Vaporization of Methylglyoxal Mimics

$247 \Delta H_{\text {vap,eff. }}$ of selected individual organic aerosol species formed from the CSTR and Batch

248 mixtures and estimated by TPD Aerosol-CIMS are given in Table 2. While oligomers might have

249 formed during the atomization and drying processes, their evolution was not observed at the

250 temperatures used. $\Delta H_{\text {vap }, \text { eff }}$ values for pyruvic acid $(\mathrm{m} / \mathrm{z} 215)$ and oxalic acid + methylglyoxal $(\mathrm{m} / \mathrm{z}$

251 217) were both lower than the theoretical $\Delta H_{\text {vap }}$ values of the pure compounds. For example, the

$252 \Delta H_{\text {vap,eff }}$ of pyruvic acid in the mixture was $\sim 5-19 \mathrm{~kJ} / \mathrm{mol}$ compared to the theoretical $\Delta H_{v a p}$ of pure

253 pyruvic acid $(48-52 \mathrm{~kJ} / \mathrm{mol})$ in the temperature range of $25-116^{\circ} \mathrm{C}$ (Yaws 2003). The reduction in

$254 \Delta H_{v a p, e f f}$ for a compound in a mixture compare to the $\Delta H_{v a p}$ of the pure compound is consistent with

255 previous findings by Ortiz-Montalvo et al. (2014), McNeill et al. (2007) and Donahue et al. (2005).

256 Changes in $\Delta H_{\text {vap,eff }}$ with $\mathrm{pH}$ are within the measurement uncertainty (Table 2). TPD Aerosol-CIMS

257 supporting data can be found in Section S2 of Supplemental Information; these results are discussed

258 in further detail below.

\section{4. Discussion and Conclusions}

In this study, effective enthalpies of vaporization were measured for mimics of the MGly +

$261{ }^{\circ} \mathrm{OH}$ precursor/product mixtures present after one cycle (10-30 min) of simulated cloud processing

$262(68 \pm 3 \mathrm{~kJ} / \mathrm{mol} ; \mathrm{VOAG})$ and for selected individual compounds in aerosols generated from the mixture

263 (5-19 kJ/mol pyruvic acid, 31-34 kJ/mol MGly + oxalic acid; TPD Aerosol-CIMS). The VOAG

264 system also measured $p_{L, \text { eff. }}^{\prime}$ of the MGly $+{ }^{\circ} \mathrm{OH}$ precursor/product mixture, $(4 \pm 7) \times 10^{7}$ atm, which 
265 decreased by only a factor of two with neutralization from $\mathrm{pH} 3$ to 7 (i.e., through addition of 266 ammonium hydroxide).

The $\Delta H_{\text {vap,eff. }}$ of the MGly $+{ }^{\circ} \mathrm{OH}$ precursor/product mixture (VOAG system) was similar

268 (Table S2) to that measured for the precursor/product mix from glycolaldehyde $+{ }^{\circ} \mathrm{OH}(\sim 70 \mathrm{~kJ} / \mathrm{mol})$

269 and glyoxal $+{ }^{\circ} \mathrm{OH}(\sim 70 \mathrm{~kJ} / \mathrm{mol})$ using the same approach (Ortiz-Montalvo et al., 2012; 2014).

270 VOAG results fell within the range of $\Delta H_{\text {vap }}$ values for the pure individual components in the

271 mixtures. The observed difference ( 40-50\%) between theoretical (molar-weighted) and VOAG-

272 estimated enthalpies reported here (Table 1) could be due to (1) compounds formed during droplet

273 evaporation (e.g., methylglyoxal oligomers, imidazoles) that were not included in the theoretical

274 calculation, and/or (2) retention of residual water in the measurements of the VOAG, which would

275 result in larger measured diameters (thus PM volume and mass) and consequently larger PM mass /

276 OM mass(droplet) ratios and higher VOAG enthalpy estimates. Based on this assessment the values we

277 report in Table 1 are likely to be upper-bound estimates. In contrast to the VOAG results for $\Delta H_{\text {vap,eff. }}$

278 of precursor/product mixtures, the (TPD Aerosol-CIMS) $\Delta H_{v a p, \text { eff. }}$ of individual compounds within

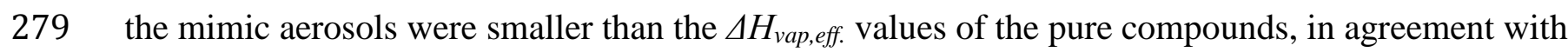

280 other TPD Aerosol-CIMS measurements of the $\Delta H_{v a p}$ of individual species within internally mixed

281 aerosol particles.

The $\Delta H_{\text {vap,eff. }}$ values obtained by the VOAG method for the MGly $+{ }^{\circ} \mathrm{OH}$ mimic mixtures are

284 CIMS method. This is not surprising since the TPD Aerosol-CIMS tracks the evolution of individual organic components from the aerosols, whereas in the VOAG experiments PM mass/OM mass(droplet) values reflect the fraction of the total mimic organic matter that remains in the particle-phase. This quantity is compared to $P M$ mass / OM mass(droplet) values for single standards of known $\Delta H_{\text {vap }, \text { eff. So }}$ the results reflect the $\Delta H_{\text {vap,eff }}$ of the entire mimic mixture and any products formed during the evaporation process (e.g., oligomers). For example, MGly is among the components of this mixture.

290 A portion of MGly will evaporate and a portion is likely to oligomerize during droplet evaporation.

291 In either case it will influence the $\Delta H_{\text {vap,eff }}$ of the mixture as measured in the VOAG. On the other 
292 hand, in the TPD Aerosol-CIMS, the $\Delta H_{\text {vap, eff }}$ values of MGly oligomers were not measured because

293 they do not volatilize at the temperatures used in our experiments $\left(\leq 116^{\circ} \mathrm{C}\right)$.

The $p_{L, e f f}^{\prime}$ of the CSTR and Batch methylglyoxal $+{ }^{\circ} \mathrm{OH}$ precursor/product mimic mixtures are

295 very similar to the $p_{L, \text { eff }}^{\prime}\left(1-2 \times 10^{-7} \mathrm{~atm}\right)$ measured for the mixture produced from the OH-initiated

296 oxidation of $(1 \mathrm{mM})$ glycolaldehyde with $\left(\sim 10^{-12} \mathrm{M}\right){ }^{\circ} \mathrm{OH}$ in a batch reactor using the same VOAG

297 system (Ortiz-Montalvo et al., 2012). In the glycolaldehyde study, we argued that the $p_{L, e f f}^{\prime}$ would be

298 orders of magnitude lower if the organic acids were neutralized ( $\mathrm{pH} 7)$ since organic salts have much

299 lower vapor pressures than the organic acids. We still believe that this is true for glycolaldehyde

300 because oxalate is a major oxidation product, at least at $40 \mathrm{~min}$, and the volatility of ammonium

301 oxalate is 4 orders of magnitude lower than that of oxalic acid (Fig. 1). Additionally, the fact that

302 oxalic acid is found in the atmosphere predominantly in the particle-phase (Limbeck et al., 2001),

303 despite its high vapor pressure, suggests that it is present in the atmosphere in a lower volatility form

304 (e.g., a salt or complex). Furthermore, in our glyoxal study we found that neutralization did in fact

305 reduce the volatility of aqueous glyoxal + ${ }^{\circ} \mathrm{OH}$ mixture (Ortiz-Montalvo et al., 2014). However, in

306 the current MGly study, the addition of ammonia (from pH 3 to 7) to the CSTR 10 min sample (i.e.

307 to form ammonium pyruvate) lowered the $p_{L, \text { eff. }}^{\prime}$ by only a factor of 2 and not orders of magnitude as

308 we expected. The degree of vapor pressure reduction is likely to depend on the properties of the

309 organic salts being formed as seen in Fig. 1. In Fig. 1, values of PM volume/OM mass (from the

310 VOAG System) and sub-cooled liquid vapor pressures are provided for pyruvic and oxalic acids and

311 their ammonium and/or sodium salts. Clearly, ammonium salt formation reduces the vapor pressure

312 of pyruvate, but not to the degree observed for oxalate. Nevertheless, atmospheric measurements

313 have found that most pyruvate is in the particle-phase (e.g., 61\%) (Limbeck et al., 2001). These

314 results and our previous findings indicate that organic salt formation can play an important role in

315 the properties and fate of SOA formed through cloud processing, but that it will depend on the gas-

316 particle partitioning of the formed salts. There is a need to better understand the predominant forms

317 that these organic acids take in the atmosphere because of their effect on gas-particle partitioning of

318 SOA. 
While this work produced a mix of lower and higher volatility products with an intermediate

320 volatility $\left(3 \times 10^{-7} \mathrm{~atm}\right.$ in the presence of ammonia), there are several ways in which the volatility of

321 MGly SOA ${ }_{\text {Cld }}$ mix might decrease further. 1) Because of its high oxygen-to-carbon ratio (O:C $\sim 0.8$ -

322 1.1), we expect this material to re-dissolve and undergo additional cloud processing cycles. Based on our model results we expect oxalate to exceed pyruvate after 10-20 cloud cycles (one or two days)

324 given $10^{-12} \mathrm{M} \mathrm{OH}$ (Fig. S3). Note that ammonium oxalate has a vapor pressure of $\sim 10^{-11} \mathrm{~atm}$ (Paciga

325 et al, 2014; Fig. 1). Thus we expect 1-2 days of cloud processing to lead to a substantial reduction in 326 the volatility of the MGly $+{ }^{\circ} \mathrm{OH}$ precursor/product mix. However if the aqueous $\mathrm{OH}$ concentration 327 is $10^{-13}$ or $10^{-14} \mathrm{M}, 20$ to more than 70 cycles (a day to in excess of a week) of cloud processing 328 would be required before oxalate dominates. Concentrations of $\mathrm{OH}$ radicals in clouds are not well 329 constrained due to an incomplete understanding of aqueous-phase $\mathrm{OH}$ production and loss,

330 especially involving organics. 2) Aqueous chemistry can also continue in the wet aerosol that is

331 present in the cloud outflow. The much higher concentrations in wet aerosols alter the chemistry and 332 promote oligomer formation through radical and non-radical reactions (DeHaan et al., 2011; Lim et 333 al., 2013). 3) The predominant chemical form of the organic acid products of MGly $+{ }^{\circ} \mathrm{OH}$ (pyruvate, 334 oxalate, acetate) in the atmosphere is not known. Binding with other cations (e.g. to form other salts) 335 or with transition metals (Weller et al., 2014) could potentially reduce the volatility of this mix. This 336 could occur via acid displacement reactions (e.g., Laskin et al., 2012) or reactions with polyvalent 337 metal ions (e.g., Furukawa and Takahashi, 2011). In conclusion, effective vapor pressure $\left(p_{L, e f f .}^{\prime}\right)$ and enthalpy of vaporization $\left(\Delta H_{\text {vap,eff. }}\right)$ values 339 were estimated for the aqueous oxidation products of methylglyoxal with ${ }^{\circ} \mathrm{OH}$ (as modeled at cloud 340 relevant conditions using two atmospheric scenarios) followed by droplet evaporation (MGly

$\left.341 \mathrm{SOA}_{\mathrm{Cld}}\right)$. The volatility assessment indicated that neutralization of MGly $+{ }^{\circ} \mathrm{OH}$ organic acid

342 products with ammonia resulted in only a modest (not statistically significant) decrease in the $p_{L, \text { eff. }}^{\prime}$

$343\left(3-6 \times 10^{-7} \mathrm{~atm}\right)$ and increase in the $\Delta H_{\text {vap,eff. }}(67-69 \mathrm{~kJ} / \mathrm{mol})$. The volatility of MGly SOACld was also 344 comparable between the Batch (MGly depletion) and CSTR (MGly at steady-state) models. Our 345 study shows that for one cloud cycle the MGly $+{ }^{\circ} \mathrm{OH}$ precursor/product mix (even neutralized) has 
an intermediate vapor pressure, meaning that a majority of this organic mixture will not remain in a

347 dry particle after droplet evaporation. There are several ways that the fraction found in the particle-

348 phase might be greater (lower volatility): (1) pyruvate (main product) could be present in a different

349 chemical form, (2) chemical processing could take place for multiple cloud cycles (one to several

350 days) to reach a maximum yield of oxalate, (3) chemical processing could continue in the wet

351 aerosol formed after droplet evaporation forming low-volatility oligomers, (4) water bound to the

352 hygroscopic particle could enhance retention of the soluble, intermediate volatility products. The

353 gas-particle partitioning of atmospheric pyruvate remains uncertain and affects our understanding of

354 methylglyoxal as a SOACld precursor.

\section{5. Acknowledgements}

This research was supported, in part, by a Ford Foundation Dissertation Fellowship Award;

Air Pollution Educational and Research Grant, Mid-Atlantic States Section of Air and Waste

Management Association; Department of Education, Graduate Assistance in Areas of National Need

(P200A060156); National Science Foundation (ATM-0630298), National Oceanic and Atmospheric

Association (NA07OAR4310279), US Environmental Protection Agency Science To Achieve

Results (RD-83375101-0), New Jersey Agricultural Experiment Station; USDA-NIFA. VFM and

ANS acknowledge support of NASA Tropospheric Chemistry (NNX09AF26G). This research was

not subjected to government agency review. It does not necessarily reflect views of any government

agency. No official endorsement should be inferred.

\section{References}

Atkinson, R., 2000. Atmospheric chemistry of VOCs and NOx. Atmos. Environ. 34, 2063-2101.

Atkinson, R., Arey, J., 2003. Atmospheric degradation of volatile organic compounds. Chem. Rev. 103, 4605-4638. Carbonyl and nitrogen dioxide emissions from gasoline-and diesel-powered motor vehicles. Environ. Sci. Technol., 42, 3944-3950.

Berglund, R.N., Liu, B.Y.H., 1973. Generation of monodisperse aerosol standards. Environ. Sci. Technol. 7, 147-153.

Betterton, E.A., Hoffmann, M.R., 1988. Henry's law constants of some environmentally important aldehydes. Environ. Sci. Technol. 22, 1415-1418.

Blando, J.D., Turpin, B.J., 2000. Secondary organic aerosol formation in cloud and fog droplets: a literature evaluation of plausibility. Atmos. Environ. 34, 1623-1632.

Carlton, A.M., Turpin, B.J. (2013) Particle partitioning potential of organic compounds is highest in 
the eastern US and driven by anthropogenic water, Atmos. Phys. Chem., 13, 10203-10214. correlation-gas chromatography. The vaporization enthalpy of RP-1, JP-7, and JP-8 rocket and jet fuels at T=298.15 K. Energy Fuels 19, 2064-2073.

De Haan, D.O., Corrigan, A.L., Tolbert, M.A., Jimenez, J.L., Wood, S.E., Turley, J.J., 2009. Secondary organic aerosol formation by self-reactions of methylglyoxal and glyoxal in evaporating droplets. Environ. Sci. Technol. 43, 8184-8190.

De Haan, D.O., Hawkins, L.N., Kononenko, J.A., Turley, J.J., Corrigan, A.L., Tolbert, M.A., Jimenez, J.L., 2011. Formation of nitrogen-containing oligomers by methylglyoxal and amines in simulated evaporating cloud droplets. Environ. Sci. Technol. 45, 984-991.

Desboeufs, K., Losno, R., Colin, J., 2003. Relationship between droplet pH and aerosol dissolution kinetics: Effect of incorporated aerosol particles on droplet $\mathrm{pH}$ during cloud processing. $\mathrm{J}$ Atmos. Chem. 46, 159-172.

Donahue, N.M., Huff Hartz, K.E., Chuong, B., Presto, A.A., Stanier, C.O., Rosenhørn, T., Robinson, A.L., Pandis, S.N., 2005. Critical factors determining the variation in SOA yields from terpene ozonolysis: A combined experimental and computational study. Faraday Discuss. 130, 295-309.

Drozd, G.T., Woo, J.L., Hakkinen, S.A.K., Nenes, A., McNeill, V.F., 2014. Inorganic salts interact with organic di-acids in submicron particles to form material with low hygroscopicity and volatility. Atmos. Chem. Phys., 14, 5205-5215.

Ervens, B., Volkamer, R., 2010. Glyoxal processing by aerosol multiphase chemistry: towards a kinetic modeling framework of secondary organic aerosol formation in aqueous particles. Atmos. Chem. Phys. 10, 8219-8244.

Ervens, B., Turpin, B.J., Weber, R.J., 2011. Secondary organic aerosol formation in cloud droplets and aqueous particles (aqSOA): a review of laboratory, field and model studies. Atmos. Chem. Phys. 11, 11069-11102.

Ervens, B., Lim, Y.B., Sorooshian, A., Turpin, B.J., 2014. Key parameters controlling aqSOA formation. J. Geophys. Res. 119, 3997-4016.

Fraser, M.P., Grosjean, D., Grosjean, E., Rasmussen, R.A., Cass, G.R., 1996. Air quality model evaluation data for organics. 1. Bulk chemical composition and gas/particle distribution factors. Environ. Sci. Technol. 30, 1731-1743.

Fu, T.M., Jacob, D.J., Wittrock, F., Burrows, J.P., Vrekoussis, M., Henze, D.K. 2008. Global budgets of atmospheric glyoxal and methylglyoxal, and implications for formation of secondary organic aerosols. J. Geophys. Res. Atmos. 113(D15) doi:10.1029/2007JD009505.

Furukawa, T., Takahashi, Y., 2011. Oxalate metal complexes in aerosol particles: implications for the hygroscopicity of oxalate-containing particles. Atmos. Chem. Phys. 11, 4289-4301.

Hakkinen, S.A.K., McNeill, V.F., Riipinen, I.A., 2014. Effect of Inorganic Salts on the Volatility of Organic Acids Environ. Sci. Technol., 48 13718-13726.

Hays, M.D., Geron, C.D., Linna, K.J., Smith, N.D., Schauer, J.J., 2002. Speciation of gas-phase and fine particle emissions from burning of foliar fuels. Environ. Sci. Technol. 36, 2281-2295.

Herrmann, H., Schaefer, T., Tilgner, A., Styler, S.A., Weller, C., Teich, M., Otto, T., 2015. Tropospheric aqueous-phase chemistry: Kinetics, mechanisms, and its coupling to a changing gas phase. Chemical Reviews. Article ASAP. DOI: 10.1021/cr500447k

Hilal, S.H., Karickhoff, S.W., Carreira, L.A., 2003. Prediction of the vapor pressure boiling point, heat of vaporization and diffusion coefficient of organic compounds. QSAR Comb. Sci. 22, 565-574.

Joback, K.G., Reid, R.C., 1987. Estimation of pure-component properties from group-contributions. Chem. Eng. Comm. 57, 233-243.

Laskin, A., Moffet, R.C., Gilles, M.K., Fast, J.D., Zaveri, R.A., Wang, B., Nigge, P., Shutthanandan, J., 2012. Tropospheric chemistry of internally mixed sea salt and organic particles: Surprising reactivity of $\mathrm{NaCl}$ with weak organic acids. J. Geophys. Res. 117, D15302. 
Lawson, S. J., Selleck, P. W., Galbally, I. E., Keywood, M. D., Harvey, M. J., Lerot, C., Helmig, D., Ristovski, Z., 2015. Seasonal in situ observations of glyoxal and methylglyoxal over the temperate oceans of the Southern Hemisphere. Atmos. Chem. Phys. 15, 223-240.

Limbeck, A., Puxbaum, H., Otter, L., Scholes, M.C., 2001. Semivolatile behavior of dicarboxylic acids and other polar organic species at a rural background site (Nylsvley, RSA). Atmos. Environ. 35, 1853-1862.

Lim, Y.B., Tan, Y., Turpin, B.J., 2013. Chemical insights, explicit chemistry, and yields of secondary organic aerosol from $\mathrm{OH}$ radical oxidation of methylglyoxal and glyoxal in the aqueous phase. Atmos. Chem. Phys., 13, 8651-8667.

Loeffler, K.W., Koehler, C.A., Paul, N.M., De Haan, D.O., 2006. Oligomer formation in evaporating aqueous glyoxal and methyl glyoxal solutions. Environ. Sci. Technol. 40, 6318-6323.

McNeill, V.F., Wolfe, G.M., Thornton, J.A., 2007. The oxidation of oleate in submicron aqueous salt aerosols: Evidence of a surface process. J. Phys. Chem. A 111, 1073-1083.

Michaud, V., El Haddad, I., Liu, Y., Sellegri, K., Laj, P., Villani, P., Picard, D., Marchand, N., Monod, A., 2009. In-cloud processes of methacrolein under simulated conditions-Part 3: Hygroscopic and volatility properties of the formed secondary organic aerosol. Atmos. Chem. Phys. 9, 5119-5130.

Millet, D.B., 2005. Atmospheric volatile organic compound measurements during the Pittsburgh Air Quality Study: Results, interpretation, and quantification of primary and secondary contributions. J. Geophys. Res. 110, D07S07.

Munger, J.W., Jacob, D., Daube, B., Horowitz, L., Keene, W., Heikes, B., 1995. Formaldehyde, glyoxal, and methylglyoxal in air and cloudwater at a rural mountain site in central Virginia. J. Geophys. Res. 100, 9325-9325.

Ortiz-Montalvo, D.L., Lim, Y.B., Perri, M.J., Seitzinger, S.P., Turpin, B.J., 2012. Volatility and yield of glycolaldehyde SOA formed through aqueous photochemistry and droplet evaporation. Aerosol Sci. Technol. 46, 1002-1014.

Ortiz-Montalvo, D.L., Häkkinen, S.A., Schwier, A.N., Lim, Y.B., McNeill, V.F., Turpin, B.J., 2014. Ammonium addition (and aerosol $\mathrm{pH}$ ) has a dramatic impact on the volatility and yield of glyoxal secondary organic aerosol. Environ. Sci. Technol. 48, 255-262.

Paciga, A.L., Riipinen, I., Pandis, S.N., 2014. Effect of Ammonia on the Volatility of Organic Diacids. Environ. Sci. Technol. 48, 13769-13775.

Pankow, J., Asher, W., 2008. SIMPOL. 1: a simple group contribution method for predicting vapor pressures and enthalpies of vaporization of multifunctional organic compounds. Atmos. Chem. Phys. 8, 2773-2796.

Peng, C., Chan, M.N., Chan, C.K., 2001. The hygroscopic properties of dicarboxylic and multifunctional acids: Measurements and UNIFAC predictions. Environ. Sci. Technol. 35, 4495-4501.

McNeill, V.F., 2015. Aqueous organic chemistry in the atmosphere: Sources and chemical processing of organic aerosols. Environ. Sci. Technol. 49, 1237-1244.

Seinfeld, John H., and Spyros N. Pandis. Atmospheric chemistry and physics: from air pollution to climate change. John Wiley Sons, 2012.

Tan, Y., Carlton, A.G., Seitzinger, S.P., Turpin, B.J., 2010. SOA from methylglyoxal in clouds and wet aerosols: Measurement and prediction of key products. Atmos. Environ. 44, 5218-5226.

Tan, Y., Lim, Y.B., Altieri, K.E., Seitzinger, S.P., Turpin, B.J., 2012. Mechanisms leading to oligomers and SOA through aqueous photooxidation: insights from $\mathrm{OH}$ radical oxidation of acetic acid and methylglyoxal. Atmos. Chem. Phys. 12, 801-813.

Tsigaridis, K., Kanakidou, M., 2003. Global modelling of secondary organic aerosol in the troposphere: A sensitivity analysis. Atmos. Chem. Phys. 3, 1849-1869.

Turpin, B. J., Lim, H.-J., 2001. Species contributions to PM2.5 mass concentrations: Revisiting common assumptions for estimating organic mass. Aerosol Sci. Technol. 35, 602-610.

U.S. EPA, 2010. Estimation Programs Interface Suite ${ }^{\mathrm{TM}}$ for Microsoft ${ }^{\circledR}$ Windows, V4.00. United States Environmental Protection Agency (U.S. EPA), Washington, DC.

Watson, K.M., 1943. Thermodynamics of the liquid state. Ind. Eng. Chem. 35, 398-406. 
483 Weller, C., Tilgner, A., Brauer, P., Herrmann, H., 2014. Modeling the impact of iron-carboxylate photochemistry on radical budget and carboxylate degradation in cloud droplets and particles. Environ. Sci. Technol. 48, 5652-5659. 


\section{Table Captions}

Table 1. VOAG results for MGly + ${ }^{\circ} \mathrm{OH}$ precursor/product mixtures: slope (PM mass / OM mass (droplet) $)$; coefficients of determination $\left(r^{2}\right)$; standard error; effective liquid vapor pressures $\left(p_{L, \text { eff. }}^{\prime}\right)$; effective enthalpies of vaporization $\left(\Delta H_{\text {vap }, \text { eff. }}\right)$.

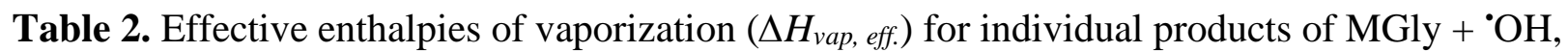
from Clausius-Clapeyron analysis of TPD Aerosol-CIMS data.

\section{Figure Captions}

Fig. 1. Ratios of residual PM volume to $O M \operatorname{mass}_{\text {(droplet) }}(P M$ vol. / OM mass(droplet) $)$ by VOAG from $1 \mathrm{mM}$ solutions of oxalic acid, ammonium oxalate, pyruvic acid, and sodium pyruvate; mixtures of 1 $\mathrm{mM}$ oxalic acid + ammonium hydroxide $(\mathrm{Amm} . \mathrm{OH})$ and $1 \mathrm{mM}$ pyruvic acid + ammonium hydroxide $(\mathrm{pH} \approx 7)$ to form ammonium oxalate (Amm. Oxalate) and ammonium pyruvate, respectively. Liquid vapor pressure $\left(p^{\circ}\right)$ estimates for acids from SIMPOL group contribution (Pankow and Asher, 2008) and for organic salts (sub-cooled $p^{\circ}{ }_{L}$ ) using EPA-EPI Suite ${ }^{\mathrm{TM}}$ (U.S. EPA 2010).

Fig. 2. (a) Batch and (b) Continuously Stirred-Tank Reactor (CSTR) model results for aqueous photooxidation of $5 \mu \mathrm{M}$ methylglyoxal (MGly) with $10^{-12} \mathrm{M}{ }^{\circ} \mathrm{OH}$. Methylglyoxal (black), pyruvic acid (pink), acetic acid (green), oxalic acid (orange), formaldehyde (blue). Pie charts provide droplet composition (molar fraction \%) at 10 and $30 \mathrm{~min}$. Background shading highlights cloud droplet lifetimes of 10-30 min (Ervens and Volkamer, 2010; Desboeufs et al., 2003).

Fig. 3. Residual particle mass (PM mass) and OM mass(droplet) formed from VOAG droplet evaporation experiments $\left(12 \pm 3 \% \mathrm{RH}\right.$ and $\left.24.1 \pm 0.4^{\circ} \mathrm{C}\right)$. OM mass (droplet $)_{\text {is }}$ the mass of organic matter in the initial droplet before evaporation. Shown are organic acid standard solutions (dashed lightcolored lines): acetic, oxalic, succinic, glutaric, tartaric acid, and mimic sample solutions (solid darkcolored lines): Batch 30 min pH 3; CSTR 10 min pH 3; CSTR 10 min pH 7. Inset: sigmoidal regression of $P M$ mass / OM mass vs. $\log p^{\circ}{ }_{\mathrm{L}}$ of standards (black squares with solid line). Inset illustrates how $p_{L, \text { eff }}^{\prime}$ of mimic samples is determined from measured PM mass / OM mass(droplet): CSTR 10 min mimic pH 7 (inset red dashed line), Batch 30 min pH 3 (inset blue dashed line), CSTR $10 \mathrm{~min} \mathrm{pH} 3$ (inset dark grey dashed line). Table 1 provides estimated effective vapor pressures and enthalpies of vaporization. 
Table 1. VOAG results for MGly + ${ }^{\circ} \mathrm{OH}$ precursor/product mixtures: slope (PM mass / OM mass (droplet) $)$, coefficients of determination $\left(r^{2}\right)$, standard error; effective liquid vapor pressures $\left(p_{L, e f f .}^{\prime}\right)$; effective enthalpies of vaporization $\left(\Delta H_{v a p, e f f .}\right)$.

\begin{tabular}{|c|c|c|c|c|c|c|c|c|}
\hline $\begin{array}{l}\text { Mimic } \\
\text { Sample }\end{array}$ & $\mathbf{p H}$ & $\begin{array}{l}\text { Density } \\
(\mathrm{g} / \mathrm{mL})\end{array}$ & Slope $^{a}$ & $\begin{array}{l}\text { Standard } \\
\text { Error }\end{array}$ & $r^{2}$ & $\begin{array}{c}p_{L, e f f .}^{b} \\
(\mathbf{a t m})\end{array}$ & $\begin{array}{l}\Delta H_{\text {vap,eff. }}{ }^{c} \\
(\mathbf{k J} / \mathbf{m o l})\end{array}$ & $\begin{array}{l}\text { Theoretical } \\
\Delta \boldsymbol{H}_{\text {vap,mix }}{ }^{d} \\
\text { (kJ/mol) }\end{array}$ \\
\hline $\begin{array}{l}\text { Batch } \\
30 \mathrm{~min}\end{array}$ & 3 & $1.2^{e}$ & 0.17 & 0.04 & $69 \%$ & $(4 \pm 4) \times 10^{-7}$ & $68 \pm 2$ & 44 \\
\hline \multirow{2}{*}{$\begin{array}{l}\text { CSTR } \\
10 \mathrm{~min}\end{array}$} & 3 & $1.1^{e}$ & 0.10 & 0.02 & $74 \%$ & $(6 \pm 6) \times 10^{-7}$ & $67 \pm 2$ & 42 \\
\hline & 7 & $1.1^{f}$ & 0.27 & 0.05 & $93 \%$ & $(3 \pm 2) \times 10^{-7}$ & $69 \pm 2$ & 42 \\
\hline
\end{tabular}

${ }^{a}$ Slopes (in units of g/g) from Fig. 3 corrected by the effect of retained water (33\% upper-bound estimate) on the density used to calculate PM mass. ST32 for organic acid standards are provided in Ortiz-Montalvo et al. (2012). ${ }^{b}$ Effective liquid vapor pressure estimates (at $298.15 \mathrm{~K}$ ) using a sigmoidal regression provided in Ortiz-Montalvo et al. (2012), which was confined by estimates of vapor pressure of pure compounds using SIMPOL group contribution method \pm error propagation (incorporates uncertainty in Pankow and Asher (2008) estimates, standard error of slope, and standard error in the coefficients of the sigmoidal regression). ${ }^{c}$ Effective enthalpy of vaporization estimates (at normal boiling point) using a sigmoidal regression provided in Ortiz-Montalvo et al (2012), which was defined by estimates of enthalpy of vaporization of pure compounds at normal boiling point \pm error propagation (incorporates uncertainty in Joback and Reid (1987), standard error of slope, and standard error in the coefficients of the sigmoidal regression). ${ }^{d}$ Molar weighted theoretical enthalpies of vaporization of product mixtures calculated following Chickos et al. (2005) approach, as $\Delta \mathrm{H}_{\mathrm{vap} \text {,mix }}=\sum_{\mathrm{i}} \mathrm{n}_{\mathrm{i}} \times \Delta \mathrm{H}_{\mathrm{vap} . \mathrm{i}}$ where $n_{i}$ is the molar fraction of species $i$ (from Fig. 2) and $\Delta H_{v a p, i}$ is the theoretical enthalpy of vaporization of species $i$ (reported in Table 2). ${ }^{e}$ Concentration-weighted density (Turpin and Lim, 2001) \pm 0.1 (error propagation accounting for the uncertainty in the concentrations). ${ }^{f}$ Assumed the same density as for CSTR 10 min pH 3 . Sensitivity analysis showed that with varying density (from 0.8 to $1.5 \mathrm{~g} / \mathrm{mL}$ ), the enthalpy of vaporization and vapor pressure were essentially unchanged (68-69 $\mathrm{kJ} / \mathrm{mol}$ and (3-2) $\times 10^{-7} \mathrm{~atm}$, respectively). 
533 Table 2. Effective enthalpies of vaporization $\left(\Delta H_{\text {vap, eff. }}\right)$ for individual products of MGly $+{ }^{\circ} \mathrm{OH}$, 534 from Clausius-Clapeyron analysis of TPD Aerosol-CIMS data.

$\Delta \boldsymbol{H}_{\text {vap, eff. }}{ }^{a}(\mathbf{k J} / \mathbf{m o l})$

\begin{tabular}{|c|c|c|c|c|}
\hline \multirow{2}{*}{$\begin{array}{l}\text { Organic } \\
\text { Species }\end{array}$} & \multirow{2}{*}{$\begin{array}{l}\text { Theoretical } \\
\Delta H_{\text {vap }} \\
\text { (kJ/mol) }\end{array}$} & \multirow{2}{*}{$\begin{array}{l}\text { Batch } 30 \mathrm{~min} \\
\text { pH } 3.8\end{array}$} & \multicolumn{2}{|c|}{ CSTR 10 min } \\
\hline & & & pH 3.7 & pH 4.6 \\
\hline $\begin{array}{l}\text { Pyruvic acid } \\
(\mathrm{m} / \mathrm{z} 215)\end{array}$ & $48-52^{b}$ & $6^{ \pm 2}$ & $19^{ \pm 9}$ & $5^{ \pm 3}$ \\
\hline $\begin{array}{l}\text { Oxalic acid / } \\
\text { Methylglyoxal } \\
(\mathrm{m} / \mathrm{z} 217)\end{array}$ & $\begin{array}{l}90-97^{b} / \\
30-35^{c}\end{array}$ & $34^{ \pm 2}$ & $31^{ \pm 5}$ & $32 \pm 3$ \\
\hline
\end{tabular}

$a$ - effective enthalpy of vaporization at $25-116^{\circ} \mathrm{C}$; average values weighted by the standard deviations $(\mathrm{n}=2) \pm$ one standard deviation (in superscript). al., 2003), and adjusted to the temperature range used in the TPD Aerosol-CIMS experiments 


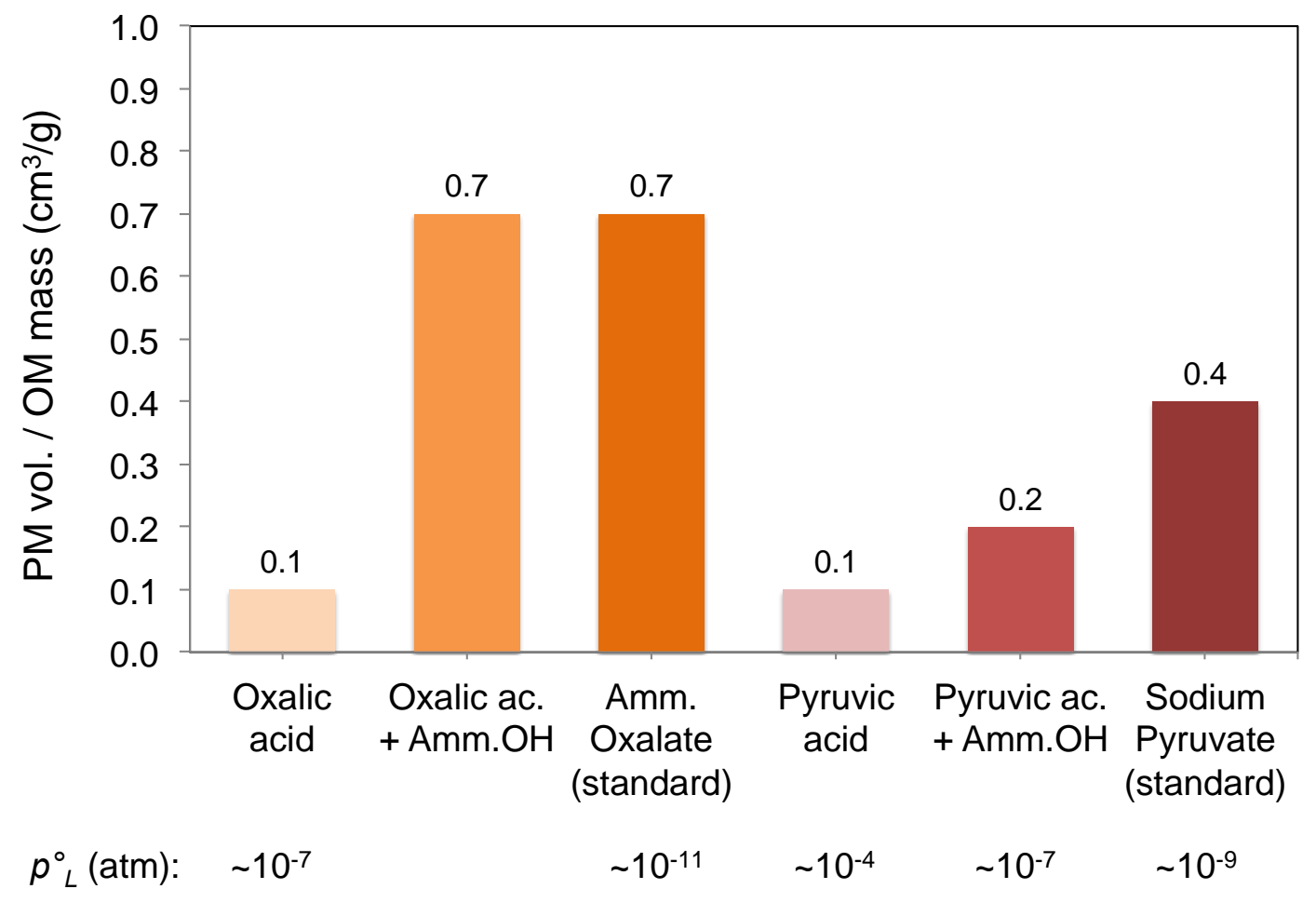

550 Fig. 1. Ratios of residual PM volume to OM mass(droplet) $(P M$ vol. / OM mass (droplet) by VOAG from $5511 \mathrm{mM}$ solutions of oxalic acid, ammonium oxalate, pyruvic acid, and sodium pyruvate; mixtures of 1 $552 \mathrm{mM}$ oxalic acid + ammonium hydroxide $(\mathrm{Amm}$. $\mathrm{OH})$ and $1 \mathrm{mM}$ pyruvic acid + ammonium 553 hydroxide $(\mathrm{pH} \approx 7)$ to form ammonium oxalate (Amm. Oxalate) and ammonium pyruvate, 554 respectively. Liquid vapor pressure $\left(p^{\circ}{ }_{L}\right)$ estimates for acids from SIMPOL group contribution 555 (Pankow and Asher, 2008) and for organic salts (sub-cooled $p^{\circ}{ }_{L}$ ) using EPA-EPI Suite ${ }^{\mathrm{TM}}$ (U.S. EPA 556 2010). 


\section{(a) Batch}
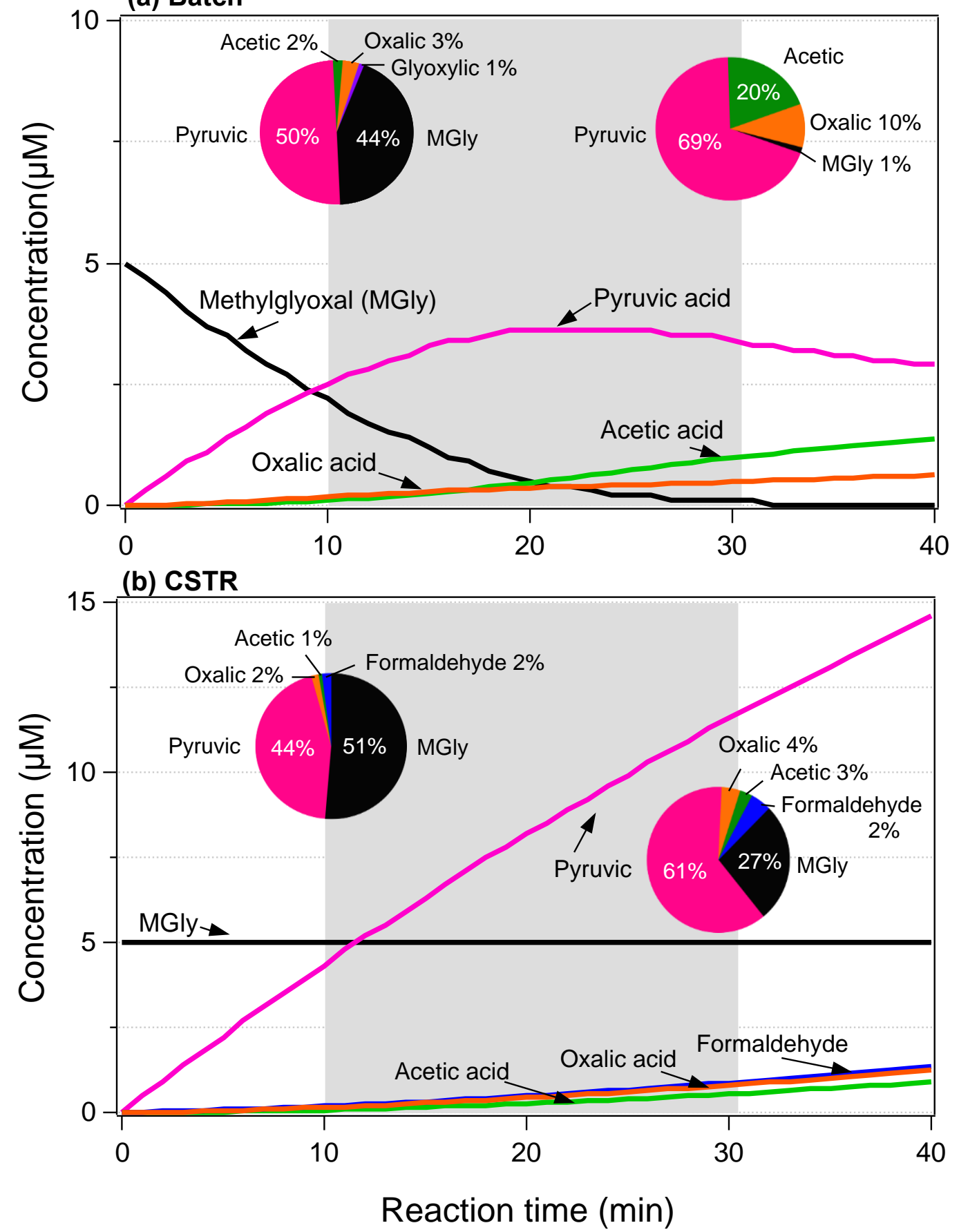

560 Fig. 2. (a) Batch and (b) Continuously Stirred-Tank Reactor (CSTR) model results for aqueous 561 photooxidation of $5 \mu \mathrm{M}$ methylglyoxal (MGly) with $10^{-12} \mathrm{M}^{\circ} \mathrm{OH}$. Methylglyoxal (black), pyruvic 562 acid (pink), acetic acid (green), oxalic acid (orange), formaldehyde (blue). Pie charts provide droplet 563 composition (molar fraction \%) at 10 and $30 \mathrm{~min}$. Background shading highlights cloud droplet 564 lifetimes of 10-30 min (Ervens and Volkamer, 2010; Desboeufs et al., 2003). 


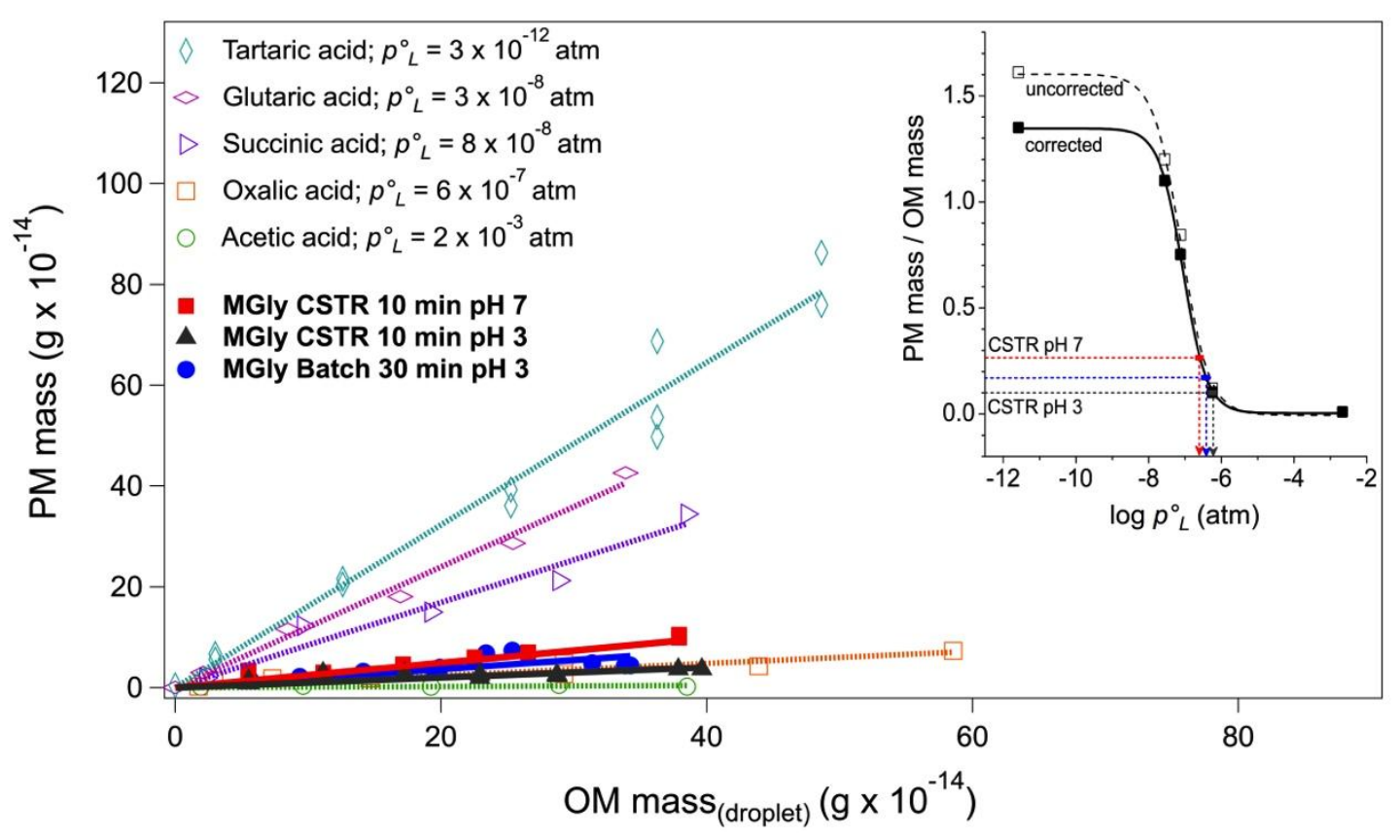

Fig. 3. Residual particle mass (PM mass) and $O M$ mass(droplet) formed from VOAG droplet

568 evaporation experiments $\left(12 \pm 3 \% \mathrm{RH}\right.$ and $\left.24.1 \pm 0.4^{\circ} \mathrm{C}\right)$. OM mass (droplet) is the mass of organic matter 569 in the initial droplet before evaporation. Shown are organic acid standard solutions (dashed lightcolored lines): acetic, oxalic, succinic, glutaric, tartaric acid, and mimic sample solutions (solid darkcolored lines): Batch $30 \mathrm{~min} \mathrm{pH}$ 3; CSTR $10 \mathrm{~min} \mathrm{pH}$ 3; CSTR $10 \mathrm{~min} \mathrm{pH}$ 7. Inset: sigmoidal regression of $P M$ mass / OM mass vs. $\log {p^{\circ}}_{\mathrm{L}}$ of standards (black squares with solid line). Inset

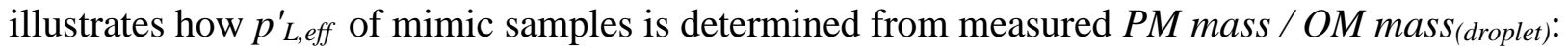
CSTR 10 min mimic pH 7 (inset red dashed line), Batch 30 min pH 3 (inset blue dashed line), CSTR 10 min $\mathrm{pH} 3$ (inset dark grey dashed line). Table 1 provides estimated effective vapor pressures and enthalpies of vaporization. 